\title{
Idioomide pildiline kujutamine internetihuumoris
}

\begin{abstract}
Tomasz Piekot
Teesid: Uue meedia, s.t interneti analüüs on tõsiseks probleemiks sõnakesksetes kommunikatsiooniuuringutes. Tavaliselt kirjeldatakse ainult žanrite verbaalset aspekti, ja teisi omadusi peetakse marginaalseteks. Käesolevas artiklis soovin arutleda selle üle, kuidas on tavaks visualiseerida idioome internetihuumoris. Heites vaid põgusa pilgu uuele meediale, on näha kaks peamist trendi: 1) idioomid esinevad erinevates uue meedia tekstitüüpides, kuid on domineerivad pigem loovtekstides; 2) idioome visualiseeritakse spontaanselt, s.t kommunikatsioonipartnerid tõlgivad neid visuaalsesse keelde. Artiklis esitatakse idioome sisaldavate demotivaatorite korpuse empiirilise uuringu tulemused. Nähtub, et loomingulise funktsiooniga tekstide puhul, eriti just huumoritekstides, allutatakse idioomid erinevatele visuaalsetele transformatsioonidele. Visuaalne tõlge võib hõlmata idioomi struktuuri (üksikuid sõnu), muutes visualiseerimise sõnasõnaliseks, või metafoorset tähendust, mispuhul on tegu kujundliku visualiseerimisega (kahes variandis - näitlikustamise või tõlgendusega). Kultuuri seisukohalt on märgatav, et idioomid ei ole internetihuumoris populaarne teema. Ainult 1,5\% kõikidest poolakeelse interneti demotiveerivatest sõnumitest kasutati idioome. Näib, et internetikasutajad on leidnud muid kujundliku tähenduse visuaalseid kandjad. Nende sotsiaalse staatuse uurimine võib saada võtmeks uue kultuuri - veebikultuuri - mõistmisel.
\end{abstract}

Märksõnad: demotivaatorid, huumor, idioom, internetikultuur, visualiseerimine

Antropoloogilisest seisukohast on inimestevaheline kommunikatsioon kultuuri säilitamise ja konsolideerimise vahend. Lingvist, kes tahab kultuuri uurida läbi keeleprisma, on peamiselt huvitatud stabiilsetest, rutiinsetest ja korduvatest ilmingutest, mille abil keele kasutajad ja kultuurikoodide kaasloojad loovad ja säilitavad oma kollektiivse identiteedi olemust, olgu selleks reaalsuse tajumise ja tõlgendamise kollektiivne moodus, aksioloogiline süsteem, või mingid muud sellised aspektid. Informatsioon mingi kultuuri ja selle omaduste kohta 
on leitav kommunikatsiooni erinevail tasandeil. Seda on võimalik ammutada grammatilisest süsteemist (nt grammatilised kategooriad, sõnaloome mustrid, lausemallid), kuid ka mittegrammatilistest nähtustest nagu sugudega seonduvad mustrid, argumentatiivsed mallid ning ka igapäevaselt kasutatavad metafoorid ja vanasõnad (Bartmiński 2009).

Üheks ajalooliselt säilinud teadmiste varamuks on idioomid, mille all peetakse silmas konventsionaliseerunud kujundlikke väljendeid (mitmesõnalisi väljendeid). Idioomidel on paljudes kultuurides kõrge staatus, seda tõika tõestavad ka erinevad sotsiaalsed praktikad. Väga sageli on idioome kogutud ja kirjeldatud eraldi sõnaraamatutes, neid õpetatakse koolides ning välismaalastele suunatud keele- ja kultuurikursustel. Samuti modifitseeritakse ja leitakse uusi tõlgendusi idioomidele kreatiivse kommunikatsiooniprotsessi käigus - reklaamides, kunstis ja ajakirjanduslikes tekstides (nt ajalehtede pealkirjades).

Idioomide kultuuriline tähtsus tuleneb tsivilisatsiooni arengukäigust. Sajandite vältel domineeris tsivilisatsiooni arengus logotsentrism, kuna keel oli olulisem kui muud kommunikatsioonivormid ja kujundas seega ka kultuurilise evolutsiooni järgnevaid etappe - alates suulisest kultuurist kuni kirjutamise ja audiovisuaalse kultuurini (Ong 2002; Hopfinger 2003). Seda konteksti arvesse võttes võib küsida: milline saab olema traditsiooniliste kultuurikandjate (nt keel) tulevik, kui kultuuriline paradigma muutub? Kas keel lakkab olemast kultuurivaramu, kui ta kaotab dominantkoodi staatuse? Kas logotsentrismi ja sõnakeskse kultuuri lõpp muudab ka metafooride, folkloori, vanasõnade ja fraseoloogia kultuurilist väärtust?

Võib öelda, et see muutus toimub otse meie silme all. Sõnakultuur (logos) asendub veebikultuuriga, ${ }^{1}$ mis evib uusi nähtusi ja sotsiaalseid praktikaid. Kõige olulisemad neist on

- uute tehnoloogiate (uue meedia) domineeriv roll kommunikatsioonis (Manovich 2001);

- virtuaalsete ja internetikogukondade ning ka uue interneti-identiteedi tekkimine (Castells 2000);

- kommunikatsioon paljude meelte (multisensoorne kommunikatsioon, virtuaalne reaalsus) ja koodide (multisemiootiline kommunikatsioon) abil (Camurri \& Rikakis 2004);

- $\quad$ semiosfääri kiire kasv (inimkeskkonna märgistamine);

- teadmuspõhise ühiskonna ülesehitamine, kus reaalsuse tajumine on asendunud reaalsuse kohta käiva informatsiooni tajumisega (McLuhan 1989, 2011; Baudrillard 1994).

Seoses kultuurilise paradigma muutumisega on huvitav jälgida, mis juhtub hääbuvat paradigma esindavate traditsiooniliste kultuurisisu kandjatega. Ise- 
äranis huvitav oleks uurida keele funktsioneerimist uues meedias, vaenulikus semiootilises keskkonnas, mis eelistab keelele teisi semiootilisi koode. Käesolevas artiklis jälgitaksegi neid protsesse, võttes lähema vaatluse alla selle, mis juhtub idioomidega internetihuumoris. ${ }^{2}$

Isegi põgus pilk uuele meediale näitab ära kaks silmatorkavat trendi, mis võiksid olla ka meie edasise analüüsi lähtepunktiks.

1. Idioome esineb erinevat tüüpi uue meedia tekstides, kuid pigem domineerivad nad just nendes, millel on loov funktsioon; see on eriti asjakohane internetihuumori puhul.

2. Idioomid on spontaanselt visualiseeritud, s.t kommunikatsioonis osalejad tõlgivad neid visuaalsesse keelde.

Viimatimainitu, mille puhul idioomid muudetakse spontaanselt digitaalseteks piltideks või kujutisteks, näib olevat iseäranis huvitav, kuna sel tegevusel on ühised tunnusjooned (Manovich 2008). Laialt levinud visualiseerimine (või laiemas tähenduses teiste semiootiliste koodide kasutamine) markeerib erinevust interneti- ja traditsioonilise kultuuri vahel; viimase puhul on visuaalne kommunikatsioon piirdunud vaid kunstiga ning seetõttu elitaarne ja eksklusiivne (nt satiirilised karikatuurid, konkreetne poeesia ${ }^{3}$ jne).

Tahan üksikasjalikumalt arutleda idioomide visualiseerimise üle, keskendudes ühele žanrile - demotivaatoritele. Selline valik on ajendatud tõigast, et demotivaatorid on üks populaarsemaid interneti-žanreid ning hõlpsasti kasutatavad ka teoreetilisest seisukohast. Nagu eespool mainitud, on idioomide tahtlik transformatsioon omane loomingulistele tekstidele või sellistele sõnumitele, mis on loodud kunstipäraste (näit poeesia), millekski keelitavate (reklaamid, ajalehtede pealkirjad) ja mänguliste (näit naljad) kommunikatsioonivormidena. Seega on demotivaatorid suisa ideaalne valdkond, kuna nad esindavad kõiki neid funktsioone - mõnikord on nad meelelahutuslikud, mõnikord refleksiivsed, filosoofilised või meelt ülendavad. Väga sageli kasutatakse neid poliitilistes debattides. Vormiliselt on demotivaatorid vägagi konventsionaliseerunud, žanrireegliks on see, et puänt tuleneb pildi ja sõna omavahelisest interaktsioonist.

Samuti tuleb meeles pidada, et internet on antud juhul kõige representatiivsem empiiriliste andmete allikas. Ta on sotsiaalseks ruumiks uut tüüpi kultuurile ja kommunikatsioonile, mis on multisemiootiline, integreerib multisensoorseid kogemusi, kombineerib erinevaid koode, ja mis peamine, on võimalik tänu uutele tehnoloogiatele.

Idioomide kontseptualiseerimisel kasutatakse käesolevas artiklis Chitra Fernando ja Roger Flavelli (1981: 17) lähenemist, mille kohaselt on idioom sõnade konstruktsioon, mis vastab kahele peamisele tingimusele: (1) idioomi tähendus ei ole selle elementide kompositsioonilise funktsiooni tulem ja (2) 
idioom on üksus, millel on kas homonüümiline sõnasõnaline analoog või vähemalt individuaalsed elemendid, mis on üksikute sõnadena mõistetavad, kuigi kogu väljendit tervikuna ei tõlgendata sõnasõnaliselt. Siin esitatud lähenemises on idioomid komplekssed väljendid, mitte lihtsad ja jagamatud keeleühikud (leksikonis), nagu see on generatiivses lingvistikas. Idioomide kompleksse olemuse hüpoteesi toetab lingvistikauurimuste korpus ning ka idioomidest ja kujundlikust mõtlemisest aru saamise kohta tehtud teadustööd (vt ülevaadet Wulff 2008). Sellele pakub tõestust ka asjaolu, et idioomide struktuur modifitseerub kommunikatsiooni käigus mitmeti (vt lisamine, väljajätted, asendamine, kontaminatsioon), ja mõnikord visualiseeritakse vaid idiomaatilise väljendi üksikuid elemente.

Seega kombineerib siinpakutud idioomide käsitlus omavahel kolme perspektiivi - kognitiivset, antropoloogilist ja multimodaalset vaatepunkti. Kognitiivses mõttes ei ole idioomid individuaalsed leksikaalsed üksused ega surnud metafoorid, vaid neil on palju komplekssemad tähendused, mida tekitavad kontseptuaalsed metafoorid, mis omakorda ühendavad idiomaatilisi väljendeid nende kujundliku tõlgendamisega (Kovecses \& Szabo 1996; Langlotz 2006). Antropoloogilisest (kultuurilisest) seisukohast on idioomid ja fraseoloogia kultuuri representeerimise ja reprodutseerimise vahendid (Cowie 1998), kus "ühte fraseoloogiapiiska on kondenseerunud terve kultuuripilv" (Wierzbicka 2007; Skandera 2007). Ja lõpuks, multimodaalsest aspektist vaadatuna on inimestel tugevad konventsionaalsed kuvandid paljude idioomide kohta (Gibbs \& O’Brien 1990); idioome illustreeritakse sageli erinevatel eesmärkidel.

\section{Veebikultuur ja demotivaatorid}

Demotivaatorid on üks populaarsemaid tänapäeva internetižanre, ja nagu nimetuski viitab, on tegu vastandiga motiveerivatele plakatitele, mida kasutatakse koolides ja kontorites. Demotivaatorite eesmärk ongi õonestada seda, mis on tavapärane ja dominantne. Artiklis käsitletu puhul tähendab see vastandumist traditsioonilistele kultuuritekstidele või väärtustele ja sellele, kuidas neid avalikkusele peale surutakse (siin: kontoritöötajate motiveerimine veenvate plakatite-postrite abil). Vastuseis või protest dominantse kultuuri suhtes, et luua alternatiivne maailm, vastandmaailm (Macek 2004) on varajase küberkultuuri peamine eesmärk. Ja kuigi see idee on praeguseks nõrgenenud, on mõned selle põhimõtted osutunud elujõuliseks ja neid leiab ka tänapäeva internetis. Interneti-identiteedi kõige olulisemad erisused - osaliselt ilmnevad need ka demotivaatorites - jagunevad kolmeks: kultuuris osalejad, suhtumine peavoolu ja meediumispetsiifiline tekstuaalsus. Vaadakem igaüht neid detailsemalt. 
Internetikultuur, pidades silmas selles osalevaid inimesi, on:

- demokraatlik - selles võivad osaleda kõik, tingimusel, et neil on juurdepääs internetti (vrd mõistega "e-tõrjutus" (e-exclusion);

- anti-elitaarne - reaalmaailma sotsiaalne staatus ei kandu üle internetti, kus sümboolset eliiti kontrollitakse ja isegi rünnatakse. Tavaliselt tekib internetis uus sümboolne eliit (nt blogijad, moderaatorid jne);

- kogukonda loov - traditsiooniline sotsiaalse rühma mõiste on internetis kasutu, kuna puudub tegelik side ja füüsiline kontakt virtuaalgrupi liikmete vahel; internetis võib täheldada selliste kogukondade teket, mis reaalses maailmas ei moodustu (nt suitsiidikalduvustega inimeste rühmad, riidemähkmeid kasutavad väikelapsevanemad, mängufanaatikud jne); samuti moodustuvad tihti lühiajalised ad hoc kogukonnad (nt flash mobs);

- normatiivne ja piirav - et internetikultuuris täielikult osaleda, ei piisa vaid tehnilistest juurdepääsuvahenditest; internetis on oma reeglid (mõnikord kasutatakse selle kohta terminit "netikett"), mis on kodifitseerivad ja väga piiravad; need reeglid kehtivad iga internetikasutaja suhtes - reeglirikkujaid kutsutakse korrale.

Oma suhtumiselt peavoolu on internetikultuur interaktiivne ja reaktiivne. See tendents on kõige selgemini nähtav poliitilises elus - internetis domineerib kriitiline suhtumine praegusesse valitsusse (küberanarhia); samuti on seal ülekaalus vähemus- ja opositsioonirühmad. Heaks näiteks on siinkohal Poola internet, mis on oma poliitikalt ja arvamusartiklites muutumas üha parempoolsemaks. Interaktiivsus ja reaktiivsus seostub ka kiirete ja sagedaste viidetega faktidele, sündmustele ja avaldustele peavoolumeedias (nt internetinaljad staaride ja poliitikute eksimuste kohta, või protestiaktsioonid internetis, mille on esile kutsunud väljaütlemised peavoolumeedias; vt ka Baran 2012).

Sõnumite osas on veebikultuurile omane

- digitaalsus - see ilmneb sõnumites, mis on loodud viisil, kus piir tõese ja vale või tõelise ja kunstliku vahel ähmastub (nt digitaalne fotomontaaž); samuti on piir ebaselge originaali ja koopia vahel (see on täheldatav traditsioonilise autoriõiguse kriisina);

- multimodaalsus - internetisõnum jääb tekstiks semiootilises mõttes, kuid sel on vähe ühist teksti kui keelelise või verbaalse sõnumi logotsentrilise tajumisega; tänapäeva internetisõnumid on multimodaalsed, mitme meelega tajutavad; interneti evolutsiooni lõppfaasis toimub kommunikatsioon ainult puhtalt virtuaalses keskkonnas;

- intertekstuaalsus - oma olemuselt viitavad internetitekstid kogu aeg teistele tekstidele; samaaegselt on tegemist erinevat tüüpi interteks- 
tuaalsusega, kus oma roll on paroodial, pastiššil, travestial, derivatsioonidel, hüpertekstuaalsusel jne.

Ülalmainitud internetikultuuri tunnusjooned on samuti omased demotivaatoritele. Iga demotivaator peaks vähemalt teoreetiliselt eitama mingit reaalset dominantkultuuris olemasolevat väärtust ning vastama väga kindlatele žanrinormidele. Veelgi enam: sageli viitavad demotivaatorid teistele tekstidele, k.a teistele demotivaatoritele, moodustades tsükli. Struktuuriliselt koosneb demotivaator neljast elemendist, kõigil neil on oluline funktsioon: tavaliselt esitatakse demotivaator mustal taustal (raam), ning see tunnus ongi selle žanri erisuseks. Pealkiri koosneb enamasti vaid ühest suurtähtedega kirjutatud sõnast. Demotivaatori teemaks on alati mingi nähtus, millel on tugev positiivne väärtus peavoolukultuuris. Tavaliselt on demotivaatori osaks ka mingi foto (väga harva mingi joonistus või film), s.t visuaalne element, millel kujutatakse olukordi naeruvääristaval või õonestaval moel, või mis eitab pealkirjas mainitud väärtuse absoluutset tõde. Demotivaatoritel on ka pildiallkiri, sõnastatud puändina või teravmeelse vastusena, mis selgitab foto tähendust.

Siinkirjeldatud struktuur on kanooniline, kuid praegusel ajal seda ka modifitseeritakse üsna sageli, kusjuures tihti piirdub muudatus vaid sellega, et rikutakse ühesõnalise pealkirja reeglit, mille asemel võib olla fraas või koguni lause. Samuti on üha rohkem demotivaatori-sarnaseid sõnumeid, kus pilt ei ole pealkirjaga konfliktis.

Demotivaatorid on demotiveerivad, sest nad riisuvad vastuvõtjalt enesekindluse, pilgates ja naeruvääristades neid enesestmõistetavusi, väärtusi ja uskumusi, mis on peavoolukultuuris ühiselt aktsepteeritud. Vaadakem lähemalt kahte näidet.
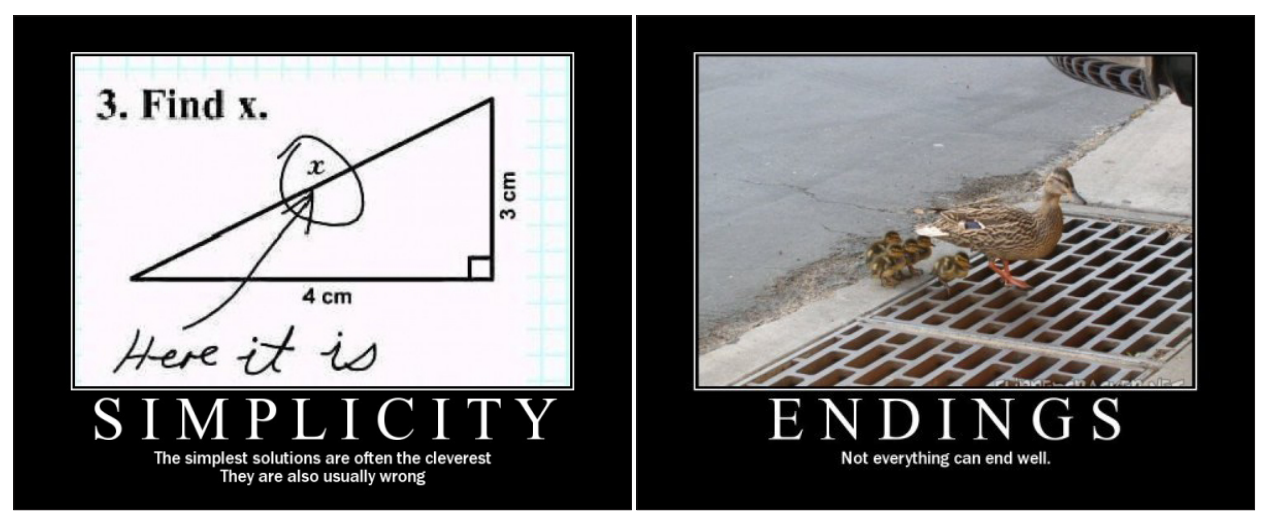

Pilt 1.

Pilt 2 .

Joonis 1. Prototüüpsed demotivaatorid. www.motivateusnot.com. 
Esimene näide (1) kuulub kategooriasse "lihtsus". Lihtsuse kultuuriline väärtus on siin visuaalselt naeruvääristatud, kasutades mingi testi või eksami fragmenti. Lihtsus, nagu puändis öeldakse, ei saa olla hea, kuna sageli on see pelgalt kavaluse tulemus ning ka liigne lihtsustamine pole õige. Teise demotivaatori

(2) puhul on kasutatud samasugust vahendit, et pilgata "õnneliku lõpu" ihalust, mis on väga populaarne müüt Lääne kultuuris.

\section{Idioomide visualiseerimise tüübid}

Vaadelgem nüüd läbiviidud empiirilisele uuringule tuginedes, kuidas idioome demotivaatorites visualiseeritakse. Uuringu tulemusena koostati idioome sisaldavate demotivaatorite korpus ning seejärel analüüsiti, kuidas neid idioome on visualiseeritud. Materjal koguti 2011. aasta septembris, mil populaarsetelt veebilehtedelt (eriti www.demotywatory.pl) salvestati 1000 järjestikust kõige kõrgema skoori saanud demotivaatorit. ${ }^{4}$ Lisaks demotivaatorite korpusele kasutati täiendavalt ka võrdlevat korpust, mis hõlmas parimaid Poola reklaamlauseid kogumikust Stownik sloganów reklamowych Hołota. Nende kahe korpuse idioomide võrdlemine võimaldas mul teha järeldusi idioomide rolli kohta tänapäeva kultuuris ja kreatiivses kommunikatsioonis. Eriti huvitasid mind kolm küsimust.

1. Kas idioomide sagedus demotivaatorites ja reklaamlausetes on suur või väike?

2. Kas reklaamlausetes ja demotivaatorites esinevad samad idioomid?

3. Kas idioomide visualiseerimise mehhanismid reklaamlausetes ja demotivaatorites on sarnased?

Analüüsi esimeses etapis võrdlesin demotivaatorite korpuses ja Poola parimate reklaamlausete korpuses esinevaid idioome. Sisuline analüüs näitas, et idioomid on mõlemas korpuses haruldased, kuid reklaamlausetes siiski pisut sagedasemad. Viiesajas parimas Poola reklaamlauses kasutati 28 idioomi, mis on kokku 5,6\%. Tuhande demotivaatori puhul aga oli idioome 15, s.t 1,5\% koguarvust. Siin on mõned näited. ${ }^{5}$ 


\begin{tabular}{|c|c|}
\hline Idioomid reklaamlausetes & Idioomid demotivaatorites \\
\hline $\begin{array}{l}\text { M\&M's - leca w kulki } \\
\text { M\&M's - lase kuulikestel lennata }\end{array}$ & $\begin{array}{l}\text { Odwrócić się do kogoś plecami } \\
\text { Kellelegi selga pöörama }\end{array}$ \\
\hline $\begin{array}{l}\text { Fortuna owocem się toczy (Fortuna) } \\
\text { Õnne puuvili (Fortuna) }\end{array}$ & $\begin{array}{l}\text { Wpaść } w \text { dołek } \\
\text { Auku kukkuma }\end{array}$ \\
\hline $\begin{array}{l}\text { Jesteś } w \text { dobrych rękach (Warta) } \\
\text { Oled heades kätes (Warta) }\end{array}$ & $\begin{array}{l}\text { Mieć niewyparzona gębę } \\
\text { Kõrvetav suu (terava keelega) }\end{array}$ \\
\hline $\begin{array}{l}\text { Ryby maja gtos (Lisner) } \\
\text { Kaladel on hääl (Lisner) }\end{array}$ & $\begin{array}{l}\text { Pracować na czarno } \\
\text { Mustal turul töötama }\end{array}$ \\
\hline $\begin{array}{l}\text { Nie drażnij lwa (Lion) } \\
\text { Ära narri lõvi (Lion) }\end{array}$ & $\begin{array}{l}\text { Gtodnemu chleb na myśli } \\
\text { Näljane mõtleb leivast }\end{array}$ \\
\hline $\begin{array}{l}\text { Nie tam się, przetam się (batonik) } \\
\text { Ära murdu - murra, et jagada (šokolaad) }\end{array}$ & $\begin{array}{l}\text { Wywrócić coś do góry nogami } \\
\text { Midagi tagurpidi pöörama }\end{array}$ \\
\hline $\begin{array}{l}\text { Palce lizać (KFC) } \\
\text { Sõrmi on hea lakkuda (KFC) }\end{array}$ & \\
\hline $\begin{array}{l}\text { Red Bull doda ci skrzydet } \\
\text { Red Bull annab tiivad }\end{array}$ & \\
\hline $\begin{array}{l}\text { Serce jak dzwon (Kama) } \\
\text { Süda nagu kell (Kama) }\end{array}$ & \\
\hline
\end{tabular}

On huvitav, et 11 idioomi esinesid nii reklaamlausetes kui ka demotivaatorites, seega võib neid pidada populaarseteks või "tugevateks" idioomideks. Demotivaatorites kasutati ka viit lendsõna või parooli, mis omakorda pärinesid idioomidega reklaamlausetest. Mõned näited. 


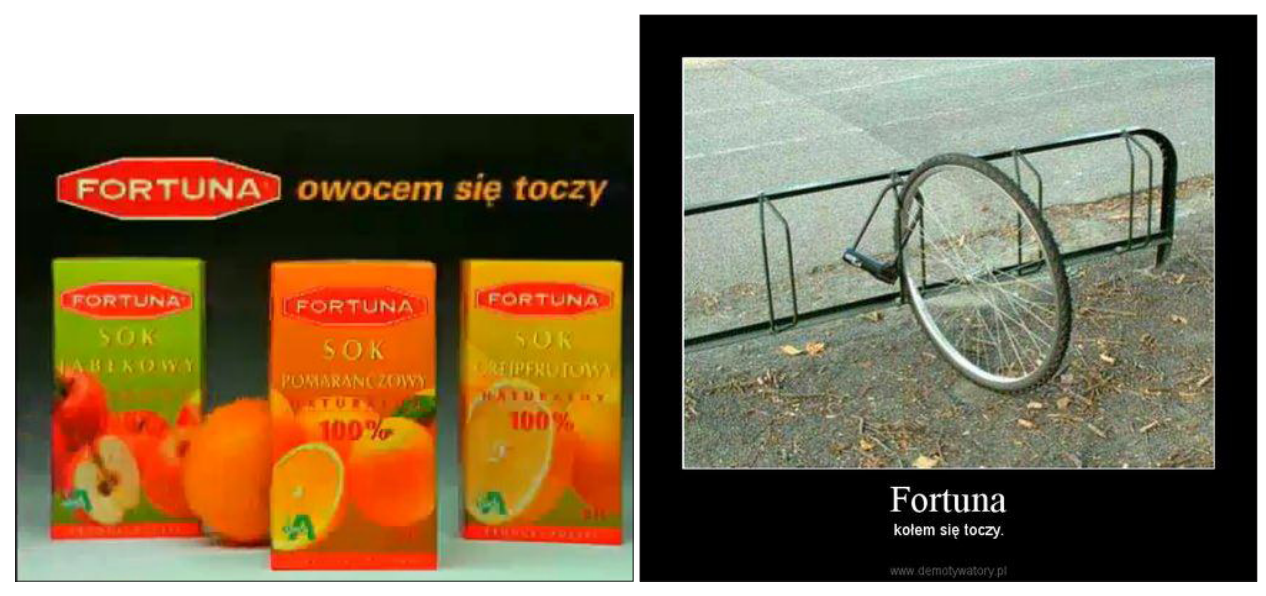

Pilt 3.

Pilt 4.

Joonis 2. Idioom “õnneratas” (Fortuna ratas) - ‘õnn tuleb ja läheb’ ${ }^{6}$ www.demotywatory.pl.

Siin on kahte visualisatsiooni ühendav element - ratas - esitatud otseses tähenduses (demotivaatori puhul) ja kujundlikult (reklaamis ümara puuviljana). Erisuseks on see, kuidas on kasutatud idioomi teist elementi, s.t sõna 'õnn/ Fortuna'. Reklaamis (3) on Fortuna lihtsalt mahla nimetus; demotivaatoris (4) on Fortuna aga saatusejumalanna, kes ei naeratanud jalgratta omanikule.

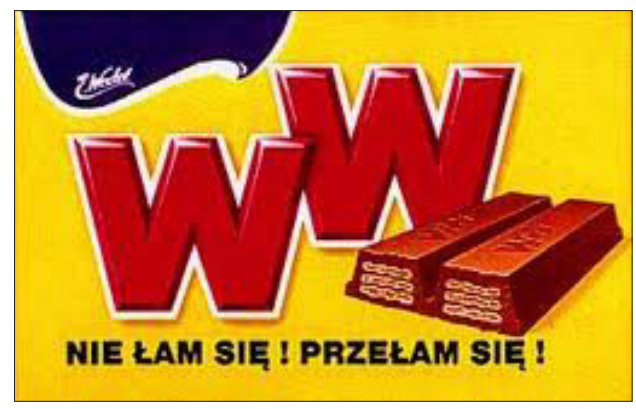

Pilt 5.

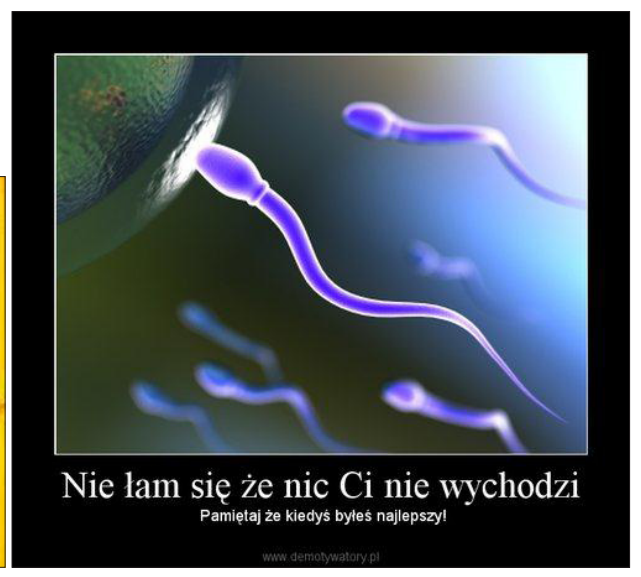

Pilt 6 .

Joonis 3. Idioom: "murdu” - 'ole murelik'. Demotivaator veebilehelt www.demotywatory.pl. 
Siin väljendab idioom “ära murdu” ('ära muretse’) samasugust kõneakti nagu reklaamiski - sellel on lohutav funktsioon. Kuid funktsioon on siin antud kahel erineval viisil. Reklaamis (5) on idioom demetaforiseeritud. Me näeme katkimurtud šokolaadibatooni, mis peaks tuju tõstma. Demotivaatoris (6) aga lohutatakse murdunud inimest, tuletades talle meelde tema väidetavalt suurimat edu - pildiallkiri ütleb: "Kunagi võitis igaüks meist elu suure võidujooksu üksiku spermatosoidina."

Üks kõige populaarsemaid idioomiga reklaamlauseid on "Kasiaga tuleb asi hästi välja”, kus Kasia on naisenimi ja ka margariinisordi nimetus.

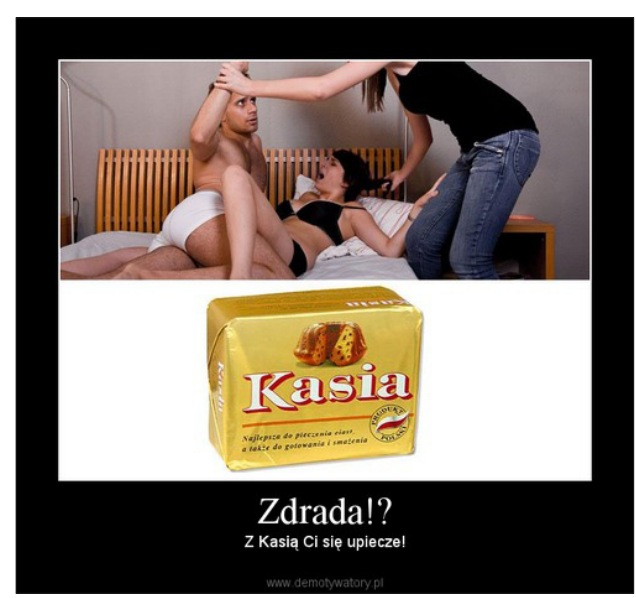

Pilt 7.

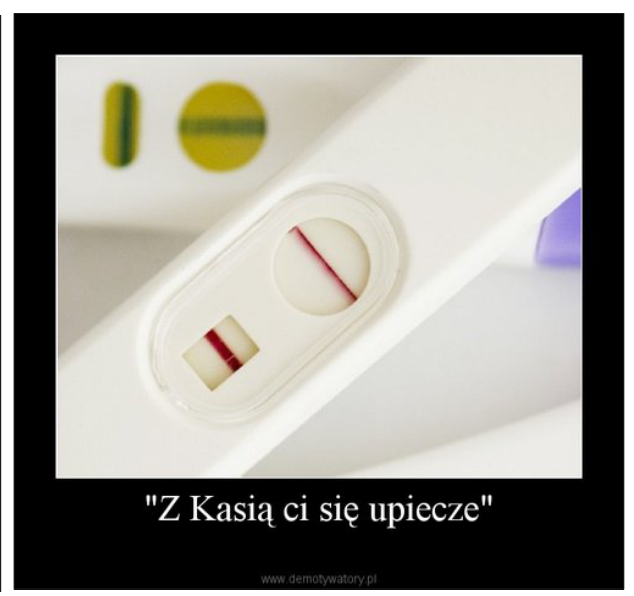

Pilt 8 .

Joonis 4. Idioom "hästi välja tulema / lõpuks millegagi hakkama saama" tähendab: 'sa tegid midagi valesti, aga suutsid tagajärgi vältida'. www.demotywatory.pl.

Originaalreklaamis isikustatakse margariin (margariini kehastab Kasia-nimeline naine), ja demetaforiseeritakse idioom (margariiniga koogid on tõepoolest maitsvad). Nagu näha, puudub originaalreklaamis idiomaatiline süü või eksimuse element. Kuid kahe demotivaatori puhul on olukord teine - siin taastatakse idioomi originaalne kujundlik tähendus. "Kasia" on jälle naine, aga negatiivseks käitumiseks on seks "Kasiaga" ja negatiivseks, kuid siiski veel välditavaks tagajärjeks on laps.

Kokkuvõttes näib, et idioomide kasutus reklaamides erineb nende kasutusviisist demotivaatorites. Reklaamides käsitatakse idioome tihti instrumentaalselt, sellest ka nende sage demetaforiseerimine ja kujundliku tähenduse kadu. 
Reklaamlause veenmistriki eesmärk on peamiselt tähelepanu püüdmine. Siis aga kantakse originaalidioomiga seonduvad väärtused või tunded üle reklaamitavale tootele, s.t mahlale omistatakse see, et ta pakub õnne (“õnnemahl”), küpsetatav kook kergendust ja rõõmu ("Kasiaga tuleb see hästi välja”). Loomulikult on demetaforiseerimine olemas ka demotivaatorites, kuid seal on pildil sageli täita lisaroll - illustreerida või näitlikustada idioomi, mida käsitatakse kui maailma kohta käiva informatsiooni allikat.

Idiomaatiliste demotivaatorite detailse analüüsi tulemusena on võimalik välja pakkuda idioomide visualiseerimismehhanismide tüpoloogia (vt joonis 5). Samas ei tohi unustada, et on olukordi, kus idioomil puudub pildiga igasugune seos. Sellisel juhul muidugi idioomi visualiseerimist ei toimu.

Selles demotivaatorite grupis, kus pilt idioomi visualiseerib, on võimalik eristada sõnasõnalist, kujundlikku ja segatüüpi visualiseerimist. Sõnasõnalise visualiseerimisega on tegu siis, kui idioomi elemendid on esitatud visuaalselt (nt ratta foto ‘õnneratas'). Kujundlik visualisatsioon aga toimub siis, kui demotivaatoris kujutatakse pildil idioomi sisulist tähendust, mitte selle sõnasõnalisi elemente. Lisaks võib kujundliku visualisatsiooni jagada veel idiomaatilise tähenduse näitlikustamiseks ja tõlgenduseks. Esimesel juhul idioomi tähendus ei muutu, kuid teisel juhul idioomi tähendust modifitseeritakse (ja seega muutuvad ka väärtused).

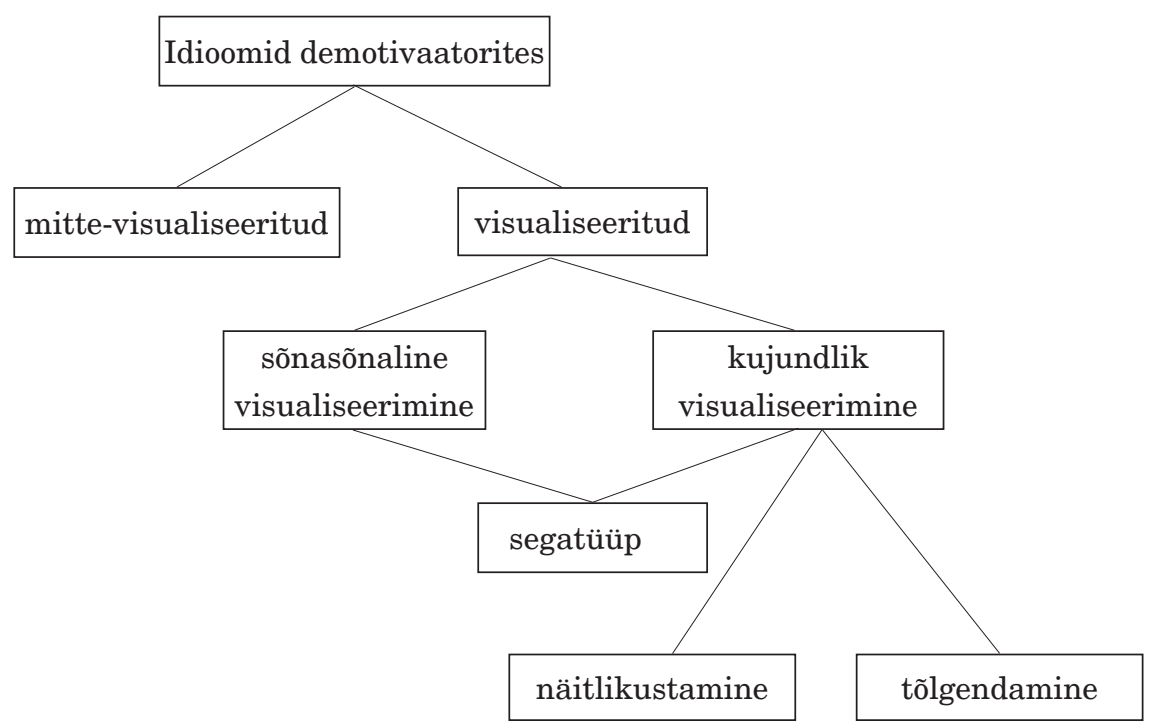

Joonis 5. Idioomide visuaalse representeerimise tüpoloogia. 
Saadud tüpoloogia nõuab detailsemat selgitust. Üks kõige populaarsemaid demotivaatorites kasutatavaid idioome on "ära narri lõvi”, ja visualiseeritud on seda kahel moel - sõnasõnalises tähenduses ning kujundlikult. Näited 9 ja 10 esindavad esimest varianti , kusjuures mõlemal pildil kujutatakse 'lõvi' otsesel, kuigi metonüümsel moel (küünejäljed). Pilt 11 on aga kujundliku visualiseerimise näide, kuna siin ei kujutata ühtegi idioomi struktuurikomponenti (s.t ei ole lõvi ega kellegi või millegi narrimist).

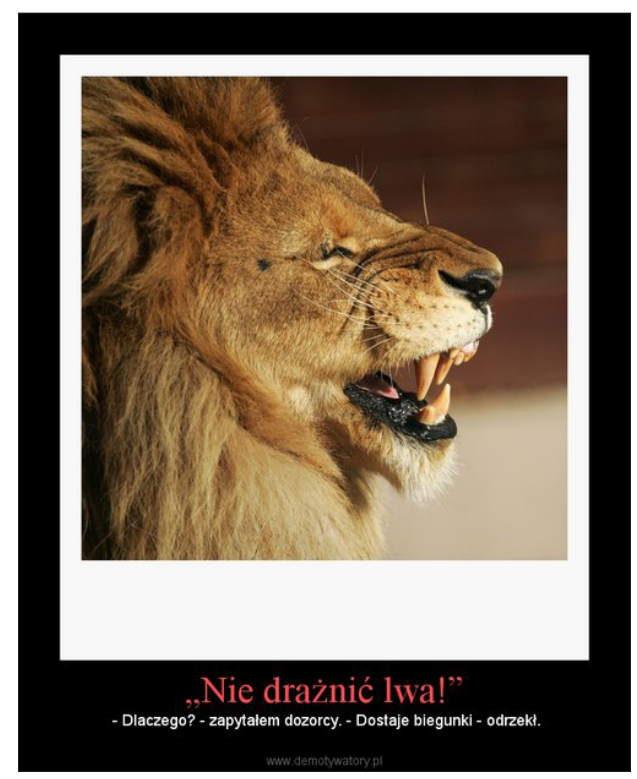

Pilt 9.

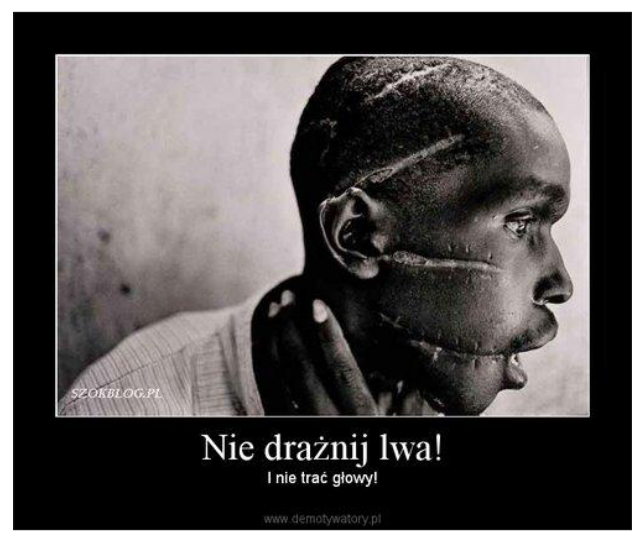

Pilt 10.

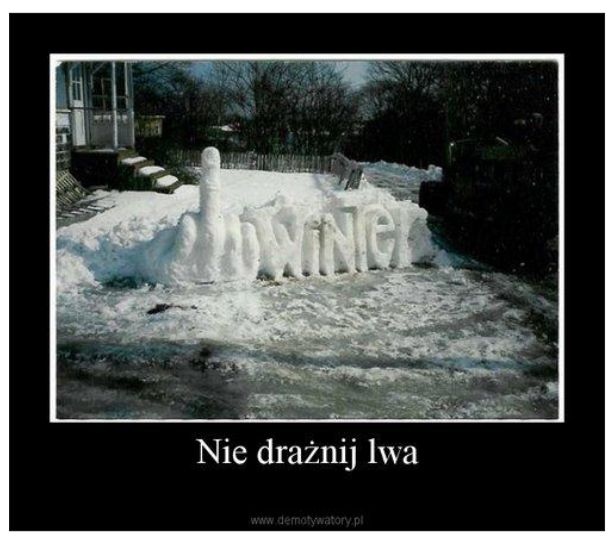

Pilt 11.

Joonis 6. Idioom "ära narri lõvi”. www.demotywatory.pl. 
Järgmised kolm näidet illustreerivad kujundlikku visualiseerimist (joonis 7). Näites 12 (idioom "kõrvetav suu" tähenduses 'terava keelega') on visuaalselt esindatud koguni kaks komponenti: 'avatud suu' ja 'kõrvetamine', s.t kuuma vee valamine. Näide 13 (idioom "laskma kellelgi endale pähe istuda") näitab sõnasõnalist tähendust 'pähe istuma', näide 14 ("piletiga lahkuma", tähendusega 'tühjade kätega ära minema') visualiseerib nii sõna "lahkuma" (tõsipidulik sõna tähistamaks suremist) kui ka sõna "pilet” (siin: lipik).

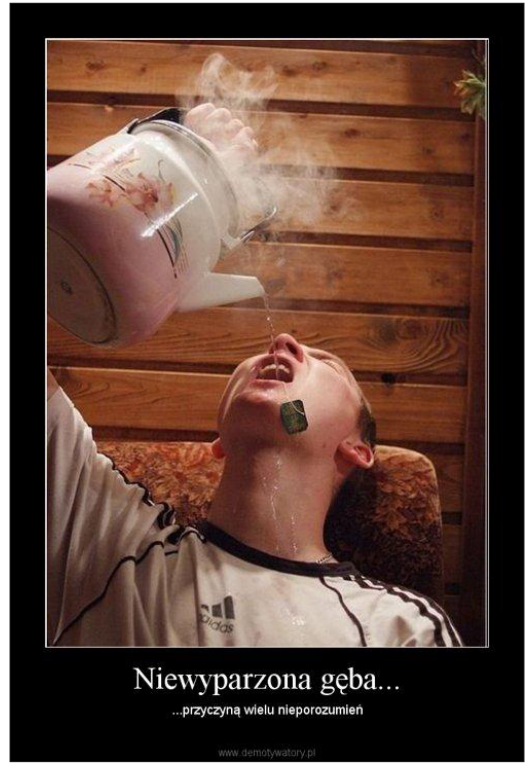

Pilt 12 .

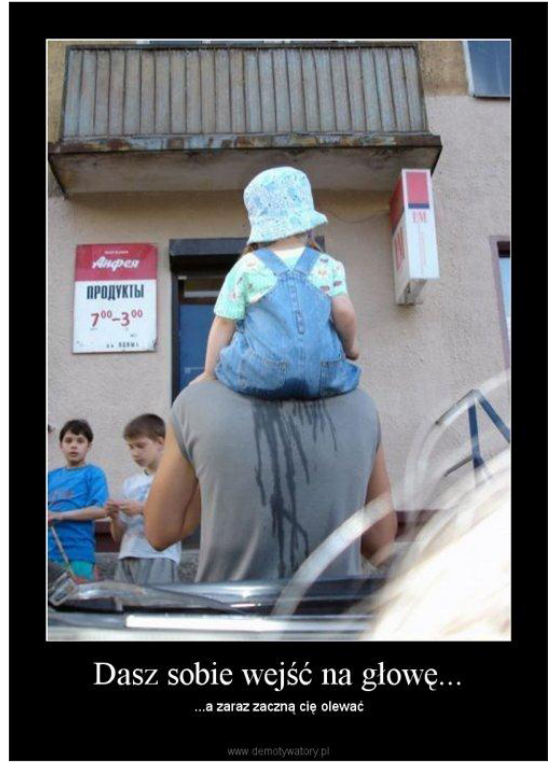

Pilt 13.

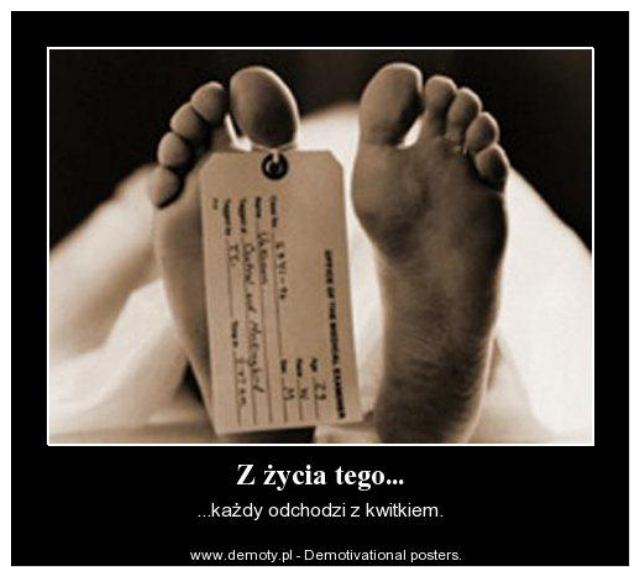

Pilt 14.

Joonis 7. Idioomide tähttähelise komponendi (sõnade) visuaalne kujutamine. www.demotywatory.pl. 
On huvitav, et sõnasõnaline visualiseerimine ei pruugi piirduda vaid idioomi ühe komponendiga. Pole sugugi tavatu, et visualiseeritakse kogu idioomi struktuur nagu näites 15 (idioom: "seintel on kõrvad") ja näide 16 (idioom "madu taskus kandma”, tähendusega 'käed rusikas olema').

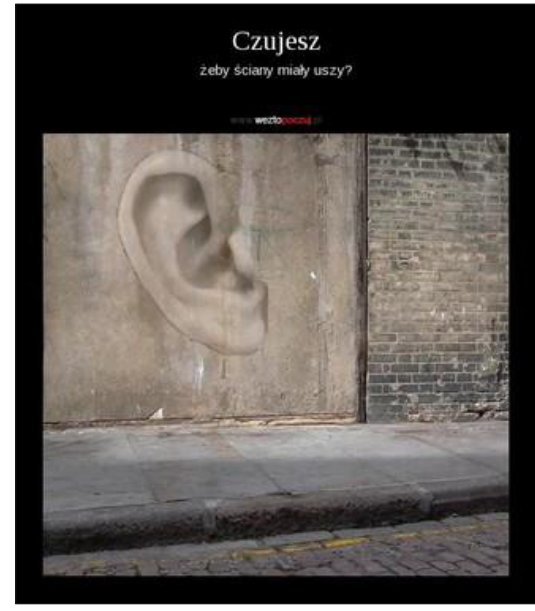

Pilt 15.

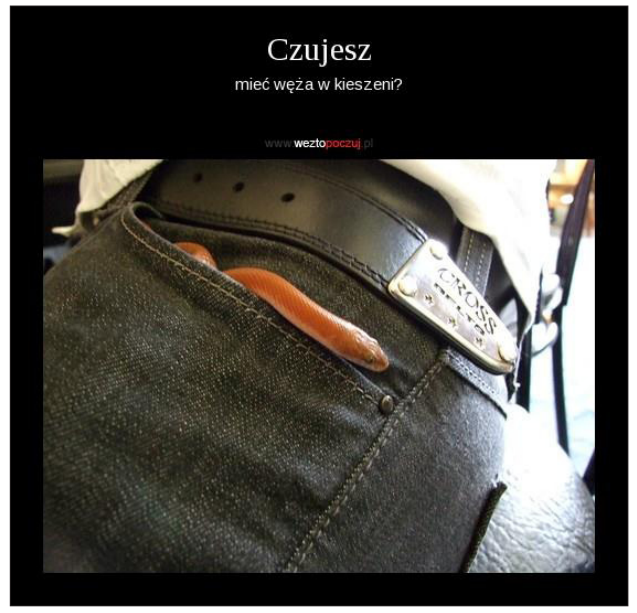

Pilt 16 .

Joonis 8. Idioomi kogu struktuuri visualiseerimine. www.demotywatory.pl.

Vaadakem nüüd idioomide kujundlikku visualiseerimist (joonis 9). Sellistel piltidel ei kujutata idioomis esinevaid sõnu, vaid idioomi kujundlikku tähendust. Tabel 1 võtab kokku kolme esitatud näite üksikasjaliku analüüsi:

\begin{tabular}{|l|l|l|l|}
\hline $\begin{array}{l}\text { Pildi } \\
\text { nr }\end{array}$ & Idioom & Tähendus & $\begin{array}{l}\text { Mis on pildil } \\
\text { näha }\end{array}$ \\
\hline $\mathbf{1 7}$ & $\begin{array}{l}\text { Näljane mõtleb } \\
\text { leivast }\end{array}$ & $\begin{array}{l}\text { Need, kes seksist mõtle- } \\
\text { vad, näevad seda kõikjal }\end{array}$ & "porgandiseks" \\
\hline $\mathbf{1 8}$ & $\begin{array}{l}\text { Alasi ja haamri } \\
\text { vahel ("kivi ja kõva } \\
\text { asja vahel") }\end{array}$ & $\begin{array}{l}\text { Olema raskes olukorras, } \\
\text { seisma silmitsi kahe } \\
\text { soovimatu alternativiga }\end{array}$ & $\begin{array}{l}\text { "Poola Hitleri ja } \\
\text { Stalini vahel" }\end{array}$ \\
\hline $\mathbf{1 9}$ & $\begin{array}{l}\text { Häda teeb } \\
\text { leidlikuks }\end{array}$ & $\begin{array}{l}\text { Me leiutame asju siis, } \\
\text { kui meil neid vaja on }\end{array}$ & $\begin{array}{l}\text { "sooja vett ei ole" } \\
\text { "elektrikann vee } \\
\text { soojendajana" }\end{array}$ \\
\hline
\end{tabular}

Tabel 1. Demotivaatorite (17), (18) ja (19) võrdlev analü̈̈s. 

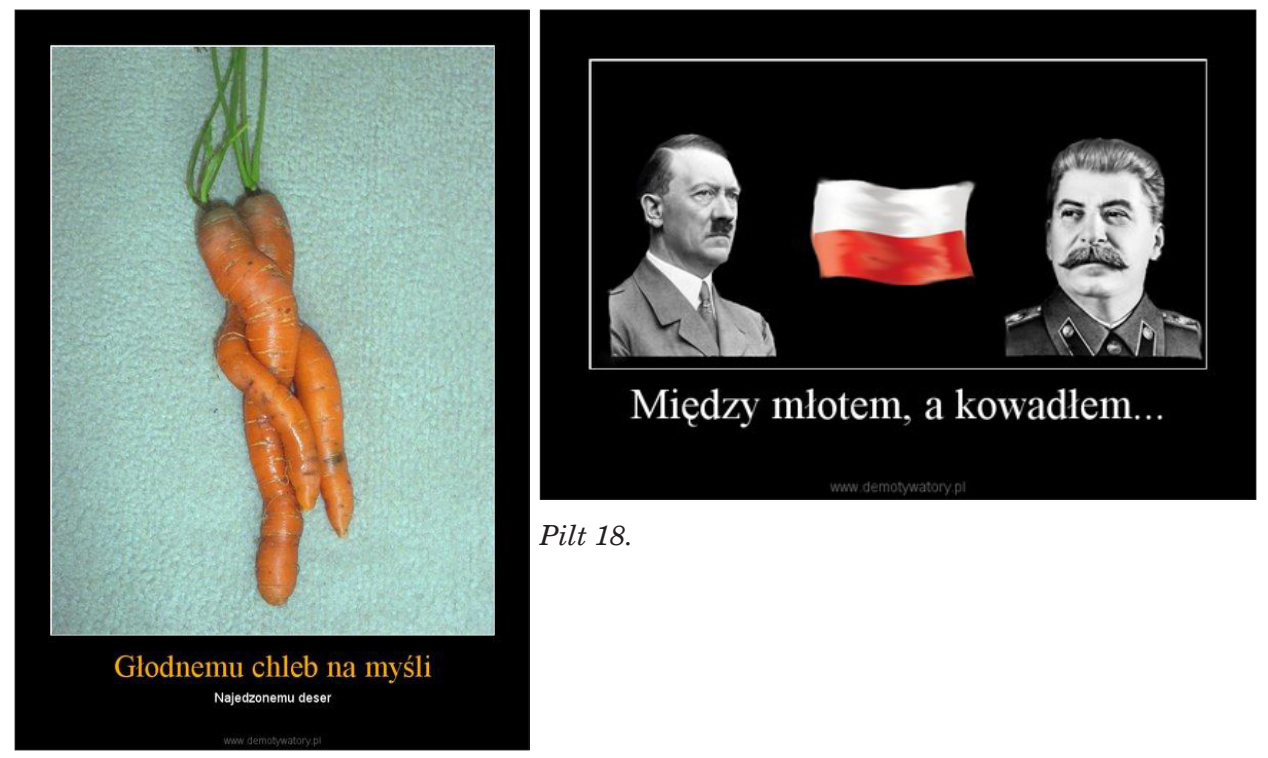

Pilt 18.

Pilt 17.

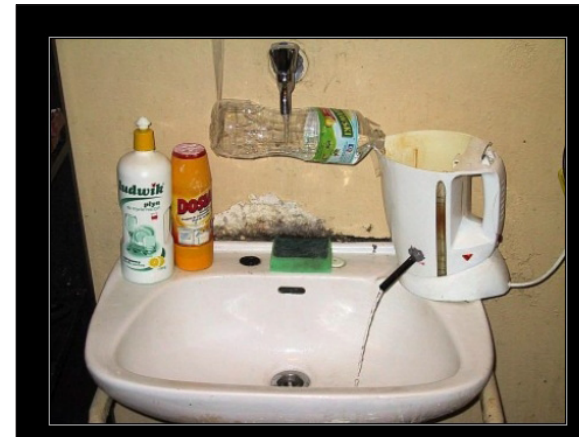

Potrzeba matką wynalazków

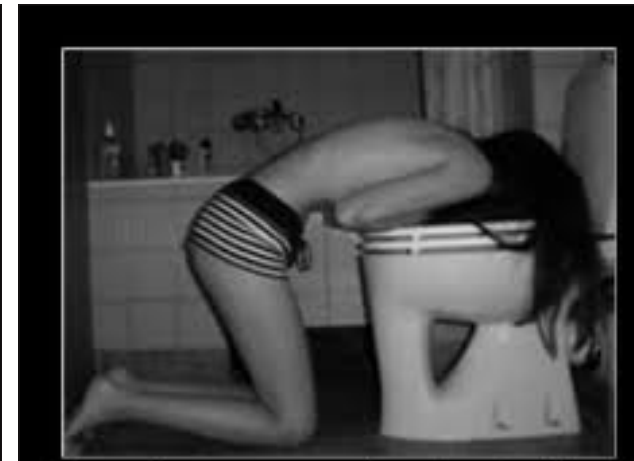

Denne imprezy pamięta się od A do Z

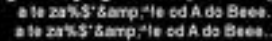

Pilt 19.

Pilt 20 .

Joonis 9. Idioomide kujundlik esitamine (kujutatud on mingit sõna idioomist). www.demotywatory.pl.

Näide 20 on pisut teistsugune, siin on idioomi tähendus ümber tõlgendatud. Idioom "jätma midagi meelde Ast kuni Zni” tähendab “midagi väga hästi meelde jätma'. Siinse demotivaatori puhul aga ei ole hea mälu positiivne, vaid negatiivne ('peo mittemäletamine tõestab, et pidu oli vägev'). 

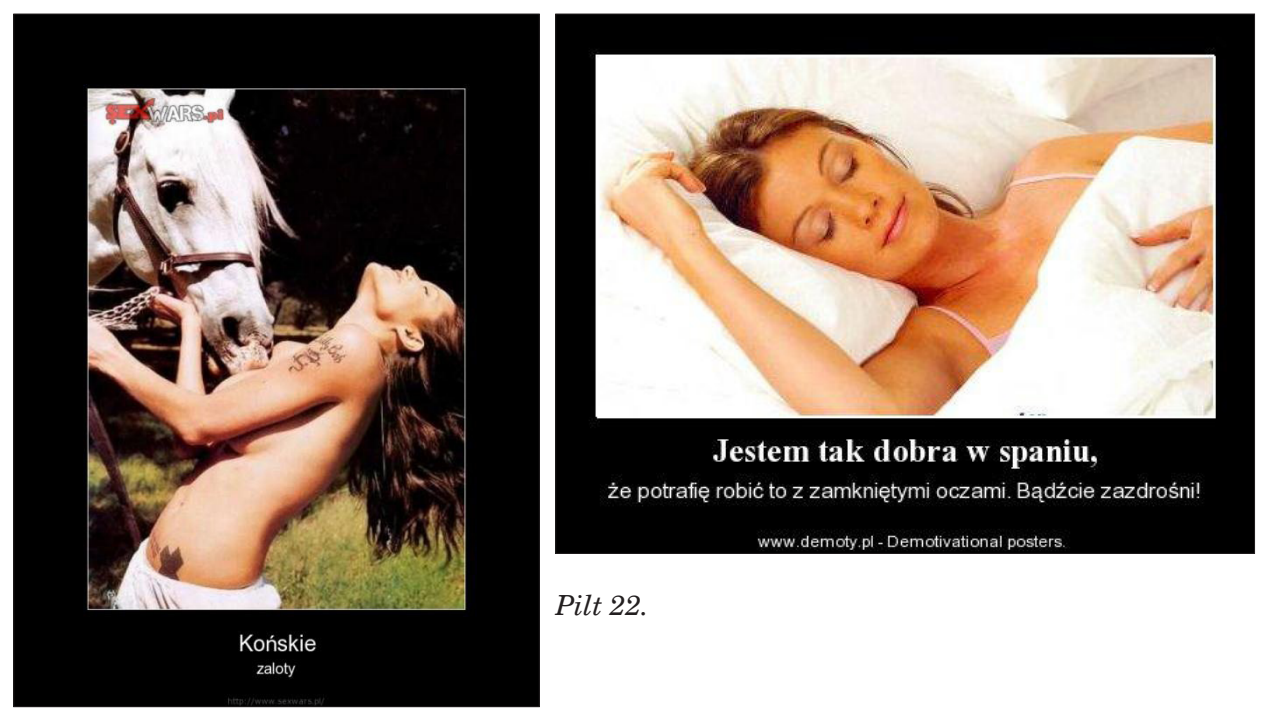

Pilt 22.

Pilt 21.

Joonis 10. Idioomide segatüüpi visualiseerimine (sõnasõnaline ja kujundlik). www.demotywatory.pl.

Ja viimasena segatüüpi visualiseerimine ehk sõnasõnalise ja kujundliku kombinatsioon - see on selgelt nähtav piltidel 21 ja 22 . Ühelt poolt esindavad need demotivaatorid idioomide verbaalseid komponente: "hobuse kuramaaž" (ingl. k. horseplay, 'ulakus'; hobuse foto) ja "midagi silmad kinni tegema” (näeme 'suletud silmi', kuid teisalt annavad mõlemad demotivaatorid edasi kujundlikke tähendusi, s.t "toores flirt" (siin: loomaga flirtimine) ja "milleski tugev olema" (siin: magamises).

\section{Kokkuvõte}

Empiirilise uuringu põhjal koostatud tüpoloogia näitab, et loovtekstides, eriti just huumoritekstides, allutatakse idioomid erinevatele visuaalsetele transformatsioonidele. Intersemiootiline tõlge võib hõlmata idioomi struktuuri (üksikud sõnad), muutes visualiseerimise sõnasõnaliseks, või selle kujundlikku tähendust - sel juhul on ka visualiseerimine kujundlik (kahes variandis; kas näitlikustav või tõlgendav). Kahe erineva visualiseerimismeetodi olemasolu võimaldab teha 
kaks peamist järeldust. Esiteks, idioomid ei ole keelega piiritletud. Igal idioomil on omaenda mentaalne representatsioon, mida saab väljendada erinevate semiootiliste koodide abil. Teiseks, idioome saab kognitiivselt kujutada kahel moel: sõnasõnaliselt ja kujundlikult.

Kultuurilisest seisukohast on märgatav, et idioomid ei ole internetihuumoris populaarne teema. Ainult 1,5\% kõikidest demotiveerivatest sõnumitest kasutati idioome. Võib eeldada, et ka kõigi teiste internetižanrite puhul on see nii, kusjuures peamiseks põhjuseks on netisuhtluse multisemiootilisus.

Kuna internetikultuuris domineerivad pildid, ei peeta idioome enam sobivaks kultuurisisu kandjaks. Internetikasutajad on niivõrd harjunud visuaalse kommunikatsiooniga, et nad on arvatavasti leidnud muud visuaalsed vahendid, mis on sama konventsionaalsed ja kujundlikud, kuid võimaldavad suuremat mängulisust. Kui peaksime määratlema mingi visuaalse nähtuse, mis on kõige sarnasem idiomaatilistele väljenditele, siis arvatavasti oleks selleks internetimeemid. Sellistel meemidel on vähemalt viis ühisjoont idioomidega: konventsionaalsus, kujundlikkus, reprodutseeritavus (neid kopeeritakse paljudes kontekstides), suur potentsiaal loovaks ja humoorikaks transformatsiooniks, ja viimasena, teatud kultuuri või sotsiaalse rühma jaoks olulise sisu säilitamine. Internetimeemid on kõige hiljutisem veebinähtus, mis on võetud teadusliku uurimise alla (Dawkins 1976; Blackmore 2000; Aunger 2002), ja selle temaatika uurimine on väidetavalt tänapäeva humanitaarteadlaste kõige suurem ülesanne. Meemide kommunikatsiooni ja kultuuristaatuse uurimine võib olla võtmeks uue kultuuri - veebikultuuri - mõistmisel.

Tõlkinud Mall Leman

\section{Kommentaarid}

${ }^{1}$ Kirjanduses on sellele uuele paradigmale antud erinevaid sümboolseid nimetusi: küberkultuur, veebikultuur, kultuur 2.0, internetikultuur jne.

2 Antud kontekstis on internetihuumor määratletud internetis leiduvate humoorikate tekstidena, mis moodustavad omaette žanreid (tekstitüüpe), ja mida kasutatakse ainult internetisuhtluses. Internetihuumori kui huumoriliigi puhul on määravaks internet/veebikultuur (vt ptk "Veebikultuur ja demotivaatorid").

${ }^{3}$ Konkreetne poeesia on luulevorm, mille puhul sõnade tüpograafiline järjestus soovitud mõju saavutamisel on sama oluline kui luuletuse tavaelemendid, nt sõnade tähendus, rütm jne.

4 Populaarsetel demotivaatorite veebilehtedel on tavaliselt kaks jaotist: nn ooteruum uute demotivaatoritega ja nn pealeht internetikasutajate poolt hääletamisel välja valitutega. Korpus koosneb 1000 unikaalsest järjestikusest pildist (ilma ühtegi pilti välja jätmata), ning allikaks on veebileht, kus demotivaatorid on populaarsuse järgi reastatud. 
${ }^{5}$ Kõik idioomid, mida demotivaatorites kasutati, on tänapäeval poola keeles hästi tuntud.

${ }^{6}$ Artiklis on läbivalt kasutatud järgmist märgistust: “" tähistab idioomi ja ' ' selle tähendust.

\section{Internetiallikad}

http://demotywatory.pl/ - 19. november 2012.

http://demotywatory.net/ - 19. november 2012.

http://www.sexwars.pl/ - 19. november 2012.

http://www.motivateusnot.com - 19. november 2012.

\section{Kirjandus}

Aunger, Robert 2002. The electric meme. A new theory of how we think. New York: Free Press.

Baran, Anneli 2012. Visual humour on the Internet. Laineste, Liisi \& Brzozowska, Dorota \& Chłopicki, Władysław (toim). Estonia and Poland: Creativity and tradition in cultural communication 1. Tartu: ELM Scholarly Press, lk 171-186.

Bartmiński, Jerzy 2009. Aspects of cognitive ethnolinguistics. London: Equinox.

Baudrillard, Jean 1994. Simulacra and simulation. Ann Arbor: University of Michigan Press.

Blackmore, Susan J. 2000. The meme machine. Oxford: Oxford UP. [Eesti keeles 2003. Meemimasin. Tallinn: Tänapäev].

Camurri, Antonioj \& Rikakis, Thanassis 2004. Guest editors' introduction: Multisensory communication and experience through multimedia. IEEE Multimedia 11 (3), lk 17-19 (doi:10.1109/MMUL.2004.9).

Castells, Manuel 2000. The rise of the network society. The Information Age: Economy, Society and Culture 1. London: Blackwell Publishers.

Cowie, Anthony Paul (toim) 1998. Phraseology: theory, analysis and applications. Oxford: Clarendon Press.

Dawkins, Richard 1976. The selfish gene. Oxford: Oxford UP.

Fernando, Chitra \& Flavell, Roger 1981. On idiom: Critical views and perspectives. Exeter Linguistic Studies 5. Exeter: University of Exeter.

Gibbs, Raymond W. \& O'Brien, Jennifer E. 1990. Idioms and mental imagery: The metaphorical motivation for idiomatic meaning. Cognition 36 (1), lk 35-68 (doi:10.1016/00100277(90)90053-M). 
Hopfinger, Maryla 2003. Doświadczenia audiowizualne. O mediach $w$ kulturze wspótczesnej [Audiovisuaalne kogemus. Meedia tänapäeva kultuuris]. Warszawa: Sic!

Kovecses, Zoltan \& Szabo, Peter 1996. Idioms: A view from cognitive semantics. Applied Linguistics 17 (3), lk 326-355 (doi:10.1093/applin/17.3.326).

Langlotz, Andreas 2006. Idiomatic creativity: A cognitive linguistic model of idiom-representations and idiom-variation in English. Amsterdam \& Phildelphia: John Benjamins.

Macek, Jakub 2004. Defining cyberculture. Binková, Pavlína \& Volek, Jaromir (toim). Média a realita. Brno: Masaryk University Press, lk 35-65 (http://macek.czechian.net/ defining_cyberculture.htm - 19. november 2012).

Manovich, Lev 2001. The language of new media. Cambridge: The MIT Press (http:// www.manovich.net/LNM/Manovich.pdf - 19. november 2012).

Manovich, Lev 2008. The practice of everyday (media) life: From mass consumption to mass cultural production? Critical Inquiry 35 (2), lk 319-331 (doi:10.1086/596645).

McLuhan, Marshall \& Powers, Bruce R. 1989. The global village. Transformations in world life and media in the 21st century. Oxford: Oxford University Press.

McLuhan, Marshall 2011. The Gutenberg galaxy. The making of typographic man. Toronto: University of Toronto Press.

Ong, Walter 2002. Orality and literacy. The technologizing of the word (2. trükk). New York: Routledge.

Skandera, Paul (toim). Phraseology and culture in English. Berlin: Mouton de Gruyter (doi:10.1515/9783110197860).

Spychalska, Marta \& Hołota, Marcin 2009. Stownik sloganów reklamowych [Reklaamlausete sõnaraamat]. Warszawa: Wydawnictwo Naukowe PWN.

Wierzbicka, Anna 2007. Reasonably well: Natural semantic metalanguage as a tool for the study of phraseology and of its cultural underpinnings. Skandera, Paul (toim). Phraseology and culture in English. Berlin: Mouton de Gruyter, lk 49-78 (doi:10.1515/9783110197860.49).

Wulff, Stefanie 2009. Rethinking idiomaticity: A usage-based approach. London \& New York: Continuum. 


\title{
Summary
}

\section{Pictorial representation of idioms in Internet humour}

\author{
Tomasz Piekot
}

Keywords: idiom, Internet culture, humour, demotivators, visualisation

The analysis of new media, i.e. Internet, is a serious problem for logocentric communication studies. Usually, only the verbal aspect of genres is described, while other qualities are seen as marginal phenomena. In this paper I want to discuss the practice of visualising idioms in Internet humour. Even a cursory glance at the new media shows two prominent trends: 1) idioms appear in various types of new media texts but tend to dominate in those with a creative function, 2) idioms are spontaneously visualised, i.e. communication partners translate them into visual language. The paper presents results of empirical studies performed on a corpus of demotivators containing idioms. It shows that creative texts, especially humorous ones, subject idioms to different visual transformations. Visual translation may involve the structure of an idiom (individual words) making the visualisation literal, or its metaphoric meaning, in which case the visualisation is figurative (in its two variants - exemplifying or reinterpreting). From the cultural perspective, is it notable that idioms are not very frequent in Internet humour. Demotivators cited idioms in only $1.5 \%$ of all demotivating messages in Polish-language Internet. It seems that Internet users have probably found other visual carriers of figurative meaning. Discovering their social status might be the key to understanding the new culture - the culture of the web. 